\title{
The MAP Kinase Kinase MKK2 Affects Disease Resistance in Arabidopsis
}

\author{
Günter Brader, ${ }^{1}$ Armin Djamei, ${ }^{2}$ Markus Teige, ${ }^{2}$ E. Tapio Palva, ${ }^{1}$ and Heribert Hirt ${ }^{2,3}$ \\ ${ }^{1}$ Viikki Biocenter, Faculty of Biosciences, Department of Biological and Environmental Sciences, Division of Genetics, \\ P.O. Box 56, FIN-00014 University of Helsinki, Finland; ${ }^{2}$ Department of Plant Molecular Biology, Max F. Perutz Laboratories, \\ University of Vienna, Dr. Bohrgasse 9, A-1030 Vienna, Austria; ${ }^{3}$ Unité de Recherche en Génomique Végétale, 2 rue Gaston \\ Crémieux, 91057 Evry cedex, France
}

Submitted 28 August 2006. Accepted 18 December 2006.

\begin{abstract}
The Arabidopsis mitogen-activated protein kinase (MAPK) kinase 2 (MKK2) was shown to mediate cold and salt stress responses through activation of the two MAP kinases MPK4 and MPK6. Transcriptome analysis of plants expressing constitutively active MKK2 (MKK2-EE plants) showed altered expression of genes induced by abiotic stresses but also a significant number of genes involved in defense responses. Both MPK4 and MPK6 became rapidly activated upon Pseudomonas syringae pv. tomato DC3000 infection and MKK2-EE plants showed enhanced levels of MPK4 activation. Although MKK2-EE plants shared enhanced expression of genes encoding enzymes of ethylene (ET) and jasmonic acid (JA) synthesis, ET, JA, and salicylic acid (SA) levels did not differ dramatically from those of wild-type or $m k k 2$-null plants under ambient growth conditions. Upon $P$. syringae pv. tomato DC3000 infection, however, MKK2-EE plants showed reduced increases of JA and SA levels. These results indicate that MKK2 is involved in regulating hormone levels in response to pathogens. MKK2-EE plants were more resistant to infection by $P$. syringae pv. tomato DC3000 and Erwinia carotovora subsp. carotovora, but showed enhanced sensitivity to the fungal necrotroph Alternaria brassicicola. Our data indicate that MKK2 plays a role in abiotic stress tolerance and plant disease resistance.
\end{abstract}

Due to their sessile life cycle, plants have developed sophisticated mechanisms to rapidly sense a changing environment and protect themselves from environmental biotic and abiotic stress. Mitogen-activated protein kinase (MAPK) cascades are common mechanisms to translate external stimuli into cellular responses in all eukaryotes, including higher plants. These protein kinase cascades consist of three subsequently acting protein kinases: a MAP kinase kinase kinase (MAPKKK), a MAP kinase kinase (MAPKK), and finally the MAPK. Different MAPK pathways respond to a variety of external stimuli and have been characterized in yeast, animals, and plants (Chang and Karin 2001; Davis 2000; Hohmann 2002; Jonak et al. 2002).

The genome of the yeast Saccharomyces cerevisiae encodes six different MAPKs, and cellular functions for five of these MAPKs have been established (Gustin et al. 1998; Herskowitz 1995; Hohmann 2002; O'Rourke et al. 2002). In contrast,

Corresponding author: H. Hirt; E-mail: Heribert.Hirt@Univie.ac.at

G. Brader and A. Djamei contributed equally to this work. plants have approximately 20 MAPKs, but relatively little is known about the function and composition of the different pathways (Jonak et al. 2002; MAPK group 2002; Tena et al. 2001; Zhang and Klessig 2001). The MAPKs investigated so far were involved mainly in stress responses (Jonak et al. 2002). In the genetic model plant Arabidopsis, MPK3, MPK4, and MPK6 are activated by a diverse set of stresses, including pathogens, osmotic, cold, and oxidative stress (Asai et al. 2002; Desikan et al. 2001; Droillard et al. 2002; Ichimura et al. 2000; Kovtun et al. 2000; Nühse et al. 2000; Petersen et al. 2000).

Compared with our current knowledge of the 20 plant MAPKs, much less is known on the functions of the 10 MAPKKs or of the more than 60 putative MAPKKKs (MAPK group 2002). As indicated by a number of biochemical studies, the presence of only 10 MAPKKs is compatible with the notion that these kinases serve as entry routes to many upstream signals as well as bifurcation points for activation of multiple downstream MAPKs (Cardinale et al. 2002; Jin et al. 2003). In Arabidopsis, MKK4 and MKK5 can activate both MPK3 and MPK6 (Asai et al. 2002), whereas MPK4 can be activated by MKK1 and MKK2 (Huang et al. 2000; Matsuoka et al. 2002; Mizoguchi et al. 1998).

Our recent biochemical and genetic analysis (Teige et al. 2004) indicated that MKK2 is an upstream activator of MPK4 and MPK6 and plays a critical role in the cold and salt stress response in Arabidopsis, but does not mediate activation of these MAPKs by the elicitors flagellin and laminarin. However, transcriptome profiling of plants overexpressing wild-type and constitutively active MKK2 revealed significant changes in the expression of a number of genes encoding proteins involved in transcriptional regulation, defense, signaling, and metabolism. Although many of the affected genes overlapped with those found in cold and salt stress (Fowler and Thomashow 2002; Kreps et al. 2002; Seki et al. 2002), a significant number was linked to plant pathogen defense responses. Therefore, we investigated whether MKK2 also could play a role in the signal transduction of pathogen defense. In this work, we show that MPK4 and MPK6 are rapidly activated upon Pseudomonas syringae pv. tomato DC3000 infection, whereas plants expressing constitutively active MKK2 (MKK2-EE plants) have enhanced levels of MPK4 activation. MKK2-EE plants are more resistant to a virulent strain of $P$. syringae pv. tomato DC3000 and Erwinia carotovora subsp. carotovora $\mathrm{SCC} 1$, but hypersensitive to Alternaria brassicicola. In contrast, no differences in sensitivity were observed of $m k k 2$ plants against $E$. carotovora subsp. carotovora SCC1 or A. brassicicola. Hormone analysis 
revealed that MKK2-EE plants were compromised in the production of jasmonic acid (JA) and salicylic acid (SA) upon infection by $P$. syringae pv. tomato DC3000. In summary, our data indicate that MKK2 is involved in both abiotic and biotic stress responses in plants.

\section{RESULTS}

\section{A number of defense-related genes are upregulated} in plants expressing constitutively active MKK2.

In our previous work (Teige et al. 2004), we produced several independent lines stably expressing constitutively active $M K K 2$ under the $35 \mathrm{~S}$ promoter of Cauliflower mosaic virus (CAMV) (MKK2-EE plants). The MKK2-EE mutant gene was tagged with an myc epitope for easier detection and isolation from plant material. Kinase activity measurements of several independent MKK2-EE lines by immunocomplex kinase assays using a MAPK-specific antibody revealed increased activity of both target MAPKs (MPK4 and MPK6) in these plants (Teige et al. 2004). For 152 genes, comparative transcript profiling using Arabidopsis ATH1 DNA microarrays from Affymetrix of wild-type plants and MKK2-EE plants revealed greater than threefold expression difference (Teige et al. 2004). Of this set of genes, 92 could be attributed to known functions and $27 \%$ of these were related to pathogen defense (Table 1). These results suggested to us that MKK2 also might function in plant pathogen defense.
Mkk2 null plants and MKK2-EE lines are oppositely affected in sensitivity

to $P$. syringae pv. tomato $\mathrm{DC} 3000$.

To investigate whether MKK2 might alter pathogen responses in Arabidopsis, we first compared the sensitivity of wild-type Col-0 plants with lines expressing constitutively active MKK2 and $m k k 2$ knock-out plants to the hemibiotrophic pathogen $P$. syringae pv. tomato DC3000. For this purpose, the previously characterized $m k k 2$ null T-DNA insertion line was compared with two lines expressing the constitutively active $M K K 2-E E$ allele expressed as myc-tagged versions under control of the constitutive $35 \mathrm{~S}$ CaMV promoter. It should be noted that $m k k 2$ null and MKK2-EE plants showed no obvious phenotype under normal ambient experimental conditions. After infection with $P$. syringae pv. tomato DC3000, no differences were observed in the development of visible disease symptoms. However, quantification of the infection process showed significant differences among the tested plant lines. MKK2-EE plants displayed significantly less bacterial growth compared with Col-0 wild-type plants $48 \mathrm{~h}$ postinoculation (Fig. 1). In comparison, $m k k 2$ null plants showed only slightly higher bacterial numbers in independent assays. Using a lower inoculum, $m k k 2$ plants allowed faster bacterial growth within 24 to $48 \mathrm{~h}$ after infection (Fig. 1B), but the data is less significant $(P \leq 0.1$, Student's $t$ test) than with the MKK2-EE lines. These data indicate that MKK2 also might be involved in basal resistance in biotrophic plant-pathogen interactions.

Table 1. Prominent up- and downregulated genes in $M K K 2-E E$ lines

\begin{tabular}{|c|c|c|c|}
\hline AGI no. & Annotation & Ratio Mkk2-EE/Col-0 & Classification \\
\hline \multicolumn{4}{|l|}{ Upregulated } \\
\hline At1g72920 & Disease resistance protein (TIR-NBS class) & 4,02 & Cell rescue, defense \\
\hline At2g34930 & Disease resistance protein family & 3,20 & Cell rescue, defense \\
\hline At2g40000 & Nematode-resistance protein & 3,83 & Cell rescue, defense \\
\hline At1g72940 & Disease resistance protein (TIR-NBS class) & 3,97 & Cell rescue, defense \\
\hline At1g66090 & Disease resistance protein (TIR-NBS class) & 3,86 & Cell rescue, defense \\
\hline At4g01250 & WRKY family transcription factor & 3,53 & Transcription \\
\hline At3g50060 & myb DNA-binding protein (MYB77) & 5,16 & Transcription \\
\hline At5g47220 & Ethylene responsive element binding factor 2 (EREBP-2) & 7,83 & Transcription \\
\hline At4g37260 & myb DNA-binding protein (AtMYB73) & 3,70 & Transcription \\
\hline At2g40140 & $\mathrm{CCCH}$-type zinc finger protein & 4,21 & Transcription \\
\hline At1g80840 & WRKY family transcription factor & 5,91 & Transcription \\
\hline At1g32640 & bHLH protein (RAP-1); identical to bHLH protein & 3,31 & Transcription \\
\hline At3g55980 & Zinc finger transcription factor (PEI1) & 4,90 & Transcription \\
\hline Atlg33760 & Transcription factor TINY & 10,11 & Transcription \\
\hline At4g31800 & WRKY family transcription factor & 5,90 & Transcription \\
\hline At5g61600 & DNA binding protein EREBP-4 & 9,70 & Transcription \\
\hline Atlg73500 & MAP kinase kinase 5 & 5,67 & Signaling \\
\hline At2g30020 & Protein phosphatase $2 \mathrm{C}(\mathrm{PP} 2 \mathrm{C})$ & 4,88 & Signaling \\
\hline At4g11280 & ACC synthase AtACS- 6 & 7,85 & Cell communication \\
\hline Atlg72520 & Lipoxygenase & 4,18 & Cell communication \\
\hline At2g06050 & 12-Oxophytodienoate reductase (OPR3) & 3,55 & Cell communication \\
\hline At1g73540 & Diphosphoinositol polyphosphate phosphohydrolase & 4,83 & Cell communication \\
\hline At5g61160 & Anthocyanin 5-aromatic acyltransferase & 6,89 & Metabolism \\
\hline At4g23600 & Tyrosine transaminase & 1,60 & Metabolism \\
\hline At5g24780 & Vegetative storage protein Vsp1 & 3,97 & Metabolism \\
\hline At1g52400 & $\beta$-Glucosidase (BG1) & 8,63 & Cell rescue, defense \\
\hline At2g43510 & Trypsin inhibitor & 1,77 & Cell rescue, defense \\
\hline Atlg60590 & Polygalacturonase & 2,22 & Cell rescue, defense \\
\hline At5g44420 & Plant defensin protein (PDF1.2a) & 3,93 & Cell rescue, defense \\
\hline At2g17840 & Senescence-associated protein 12 & 3,17 & Unknown role \\
\hline At1g54040 & Jasmonate inducible protein & 3,35 & Cell rescue, defense \\
\hline At3g 16390 & Lectin & 3,79 & Cell rescue, defense \\
\hline \multicolumn{4}{|c|}{ Downregulated } \\
\hline At2g32680 & Disease resistance protein family & 0,75 & Cell rescue, defense \\
\hline At4g38860 & Auxin-induced protein & 0,30 & Transcription \\
\hline At1g29430 & Auxin-induced protein & 0,31 & Transcription \\
\hline At4g38840 & Auxin-induced protein & 0,27 & Transcription \\
\hline At1g21250 & Wall-associated kinase 1 & 0,75 & Cellular communication \\
\hline
\end{tabular}


MKK2-EE plants show enhanced MPK4 activation upon $P$. syringae pv. tomato DC3000 infection.

To assay directly for a dependency of the activation of MPK4 and MPK6 upon pathogen infection in vivo, Arabidopsis plants were infiltrated with $P$. syringae pv. tomato DC 3000 and protein extracts were prepared at 0,20 , and 30 min after infiltration. Endogenous MPK4 and MPK6 kinases were immunoprecipitated from these extracts with specific antibodies followed by determination of their protein amounts by Western analysis and kinase activities using MBP as a substrate. In wild-type plants, MPK4 and MPK6 both become rapidly activated within 20 min after infection (Fig. 2A). The activation clearly was a post-translational regulation, because MPK4 and MPK6 protein amounts did not change under these conditions (Fig. 2A).

When MKK2-EE plants were analyzed for MPK4 and MPK6 activation by $P$. syringae pv. tomato DC3000, we observed activation of both kinases within 20 min (Fig. 2B, 20 min). When compared with Col-0 plants, levels of MPK6 activation were quite comparable upon $P$. syringae pv. tomato DC3000 infection, but those of MPK4 clearly exceeded those seen in wild-type plants (Fig. 2A and 2B, Pst DC3000). The enhanced MPK4 activation in MKK2-EE plants could be partially explained by the fact that increased MPK4 kinase activity levels already were observed in untreated plants (Fig. 2B, 0 min). As shown by comparative Western analysis with Col-0 plants (Fig. 2A and 2B, $0 \mathrm{~min}$ ), the enhanced kinase activity of MPK4 in MKK2-EE plants clearly is not due to increased MPK4 protein levels.

When $m k k 2$ null mutant plants were analyzed, MPK4 and MPK6 activity levels, as well as protein amounts in untreated plants, were similar to those found in wild-type Col- 0 plants (Fig. 2C and A, respectively). Upon infection of $m k k 2$ mutant plants by $P$. syringae pv. tomato DC3000, the activation profiles of MPK4 was reduced at $30 \mathrm{~min}$ but not at $20 \mathrm{~min}$, whereas MPK6 kinase activation was comparable with wildtype Col-0 plants (Fig. 2C and A, respectively). The data suggest that another MAPKK is present in $m k k 2$ mutants that can still mediate the pathogen-induced activation of the two MAPKs.

To control whether the infiltration treatment might be sufficient to activate the MAPKs, we also carried out mock infections with buffer alone. Under these conditions, MPK4 and MPK6 showed only limited activation (Fig. 2A through C, mock), indicating that the mechanical and osmotic stress components in the $P$. syringae pv. tomato DC3000 infection process were not responsible for the changes observed in MAPK activities.

\section{Altered levels of JA in MKK2-EE plants.}

Transcriptome analysis of MKK2-EE plants indicated upregulation of genes involved in synthesis of ethylene (ET) (ACC synthase ACS6) and JA (lipoxygenase and 12-oxophytodienoate reductase $O P R 3$ ). These data suggested to us that these plants might accumulate increased levels of ET and JA. In line with these expectations, MKK2-EE lines showed enhanced transcript levels of the ET/JA marker gene PDF1.2. Accumulation of SA, JA, and ET has been implicated as a signal for activation of plant defense responses and plant pathogen resistance; therefore, we characterized the levels of SA, JA, and ET in the different lines before and after infection with $P$. syringae pv. tomato DC3000. SA levels in mocktreated $m k k 2$ null and MKK2-EE lines were comparable with those in wild-type plants (Fig. 3A). After $48 \mathrm{~h}$ of infection by $P$. syringae pv. tomato DC3000, accumulation of SA was observed in all lines, although MKK2-EE lines clearly showed 30 to $40 \%$ lower amounts of SA $48 \mathrm{~h}$ postinoculation (hpi)
(Fig. 3A). Although MKK2-EE lines showed strong upregulation of ACS6, ET production before and after infection by $P$. syringae pv. tomato DC3000 was comparable with that seen in wild-type plants (Fig. 3B). In $m k k 2$ null plants, however, lower ET levels were observed before and after infection, but other independent experiments did not show such a clear correlation. When JA levels were determined, no major differences were observed between $m k k 2$ null and wild-type plants either before or after infection with $P$. syringae pv. tomato DC3000 (Fig. 3C). Despite the fact that MKK2-EE plants have increased lipoxygenase and $O P R 3$ levels, these plants showed even slightly lower JA levels in the uninfected state. Interestingly, upon infection with the bacterial pathogen, the accumulation of JA was strongly compromised in MKK2-EE plants when compared with Col-0 wild-type and $m k k 2$ plants, and JA levels 48 hpi were almost back to the same levels as in the mock-treated MKK2-EE plants. These results indicate that MKK2 is involved in modulating hormone levels in response to pathogen infection.

\section{MKK2-EE plants are impaired in resistance} against infection by the necrotrophic fungus $A$. brassicicola.

JA is an important regulator of defense and, here, especially against nectrotrophic pathogens. In Arabidopsis, resistance to A. brassicicola relies on JA-dependent defense mechanisms and the capability to produce the phytoalexin camalexin (Thomma et al. 1999). Mutants incapable of synthesizing JA, such as those defective in three fatty acid desaturases (triple $\mathrm{fad}$ ), or insensitive to JA, such as coil as well as pad3 unable to accumulate camelexin, are susceptible to infection by this necrotrophic pathogen (Thomma et al. 1998, 1999). To investi-
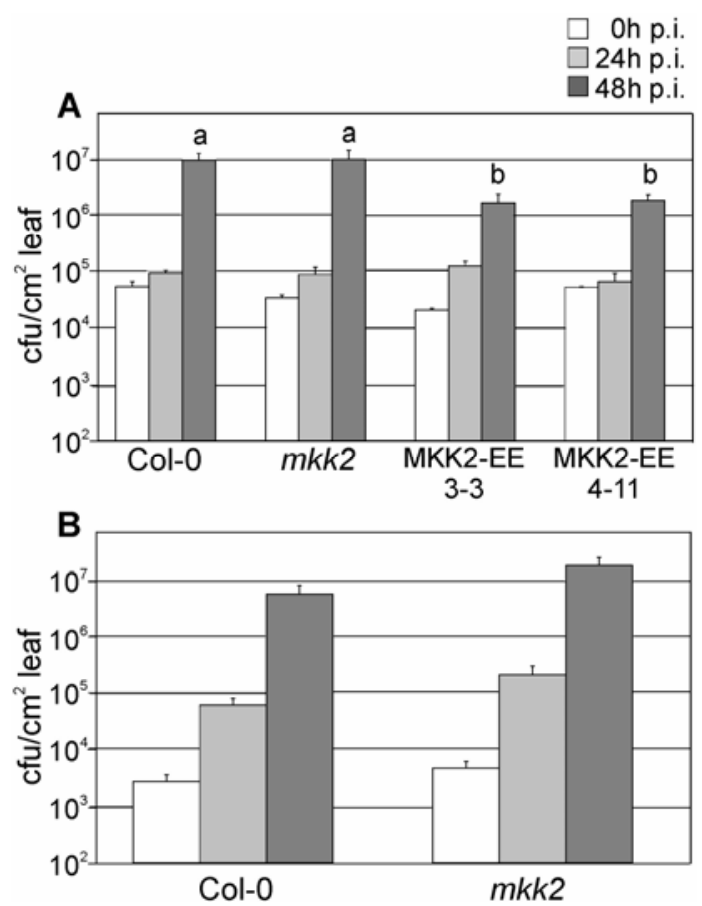

Fig. 1. Differentially affected sensitivity of mitogen-activated protein kinase kinase $2(m k k 2)$ null and MKK2-EE plants to infection by Pseudomonas syringae pv. tomato DC3000. Growth of $P$. syringae pv. tomato DC3000 in wild-type, MKK2-EE, and $m k k 2$ null plants after infection by dipping. Bars represent the bacterial titers of three pooled leaf disks in six replicates ( \pm standard error) obtained at different time points after infection. Plants were dipped in $10 \mathrm{mM} \mathrm{MgSO}_{4}$ containing $\mathbf{A}, 8 \times$ $10^{6}$ or $\mathbf{B}, 2 \times 10^{5} \mathrm{CFU} / \mathrm{ml}$; h p.i. $=$ h postinoculation. Significant differences 48 h p.i. $(P<0.05)$ were calculated by one-way analysis of variance with a least significant difference test and are indicated by different letters. 


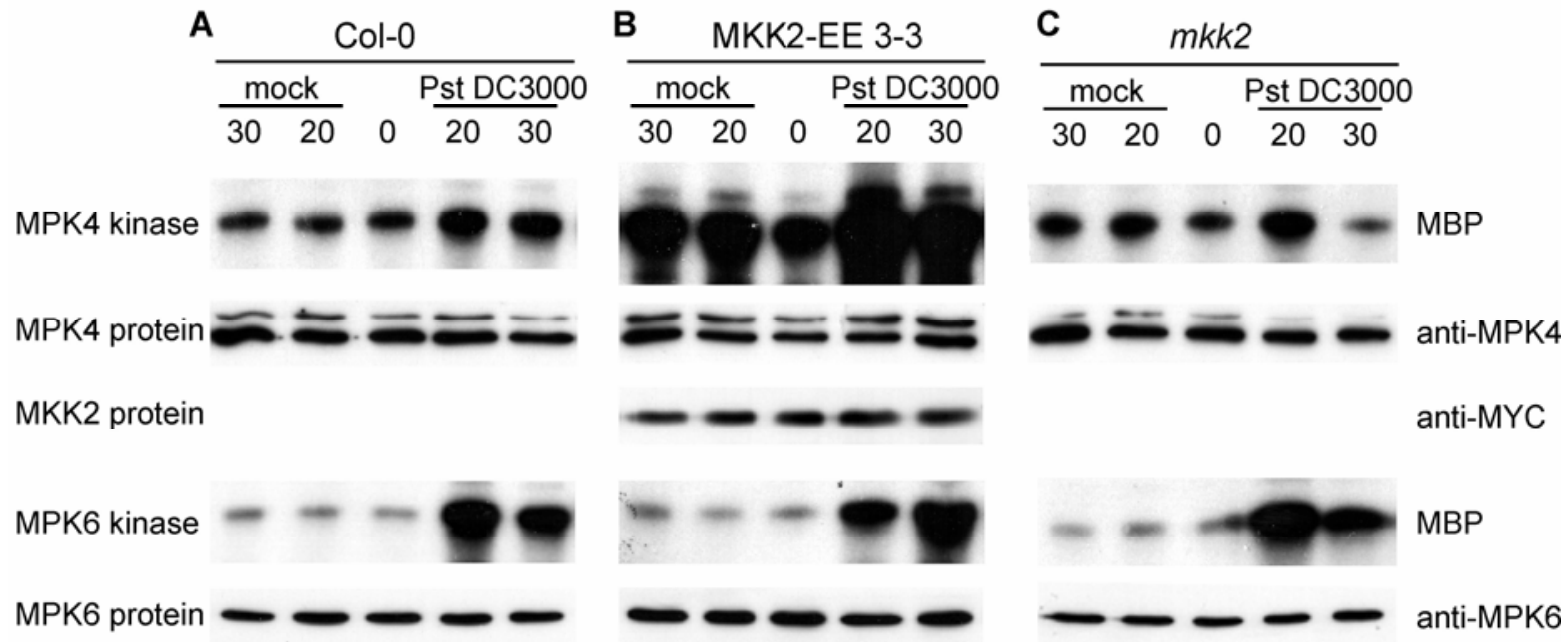

Fig. 2. Enhanced activation of mitogen-activated protein (MAP) kinase 4 (MPK4) by Pseudomonas syringae pv. tomato DC3000 infection in MAP kinase kinase 2 (MKK2-EE) plants. Kinetics of MPK4 and MPK6 activation in A, wild-type Col-0; B, MKK2-EE 3-3; and $\mathbf{C}$, $m k k 2$ null plants in response to P. syringae pv. tomato DC3000 infection. MPK4 and MPK6 were immune precipitated with specific antibodies from leaves of $P$. syringae pv. tomato DC3000infected plants as described in the experimental procedures. MPK activity was measured in immunocomplex kinase assays using MBP as substrate and levels of MPK4 and MPK6 proteins were detected in Western blots.

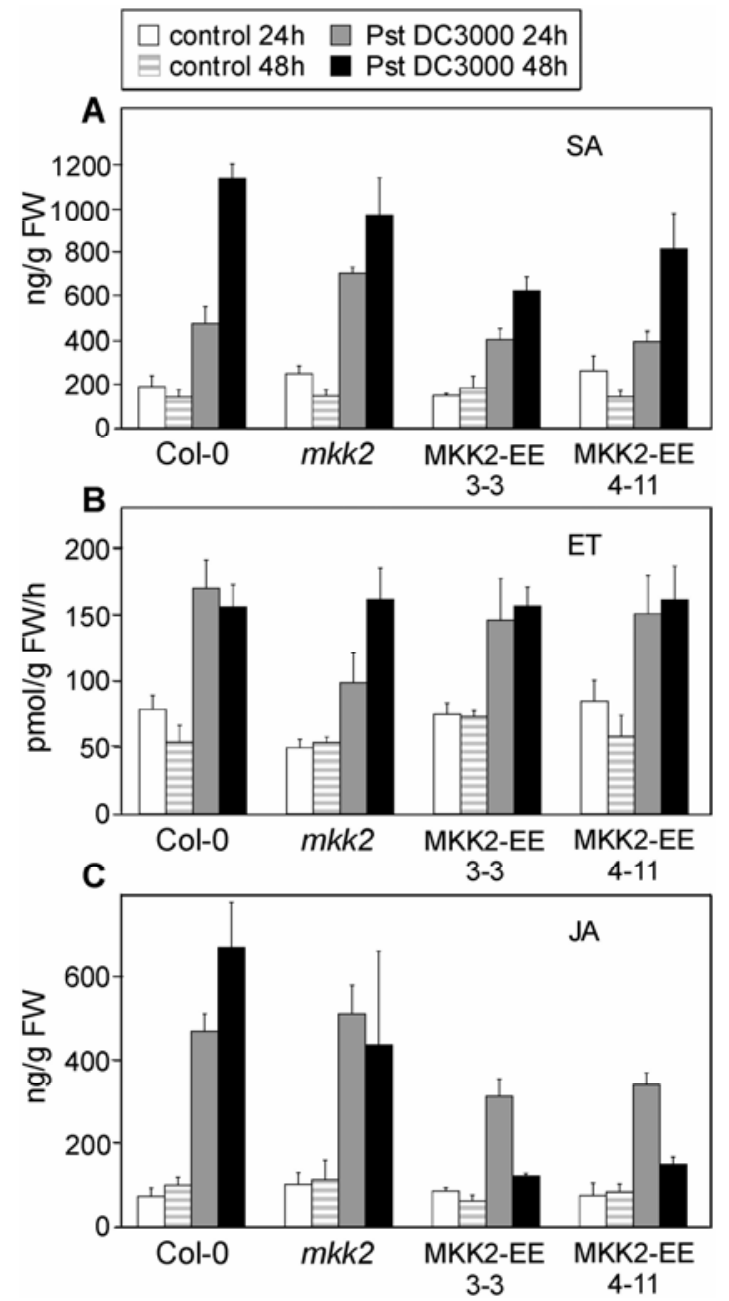

Fig. 3. Determination of salicylic acid (SA), jasmonic acid (JA), and ethylene (ET) in mitogen-activated protein kinase kinase 2 (MKK2-EE) plants after infection by Pseudomonas syringae pv. tomato DC3000. A, SA; B, ET; and C, JA were determined in wild-type Col-0, $m k k 2$ null, and two different MKK2-EE lines 24 and $48 \mathrm{~h}$ after infection with $P$. syringae pv. tomato DC3000 $\left(8 \times 10^{6} \mathrm{CFU} / \mathrm{ml}\right.$; Pst DC3000) or mock inoculation with $10 \mathrm{mM} \mathrm{MgSO}{ }_{4}$ containing $0.02 \%$ Silwet-20 (control). The values represent the average of three replicates \pm standard error.
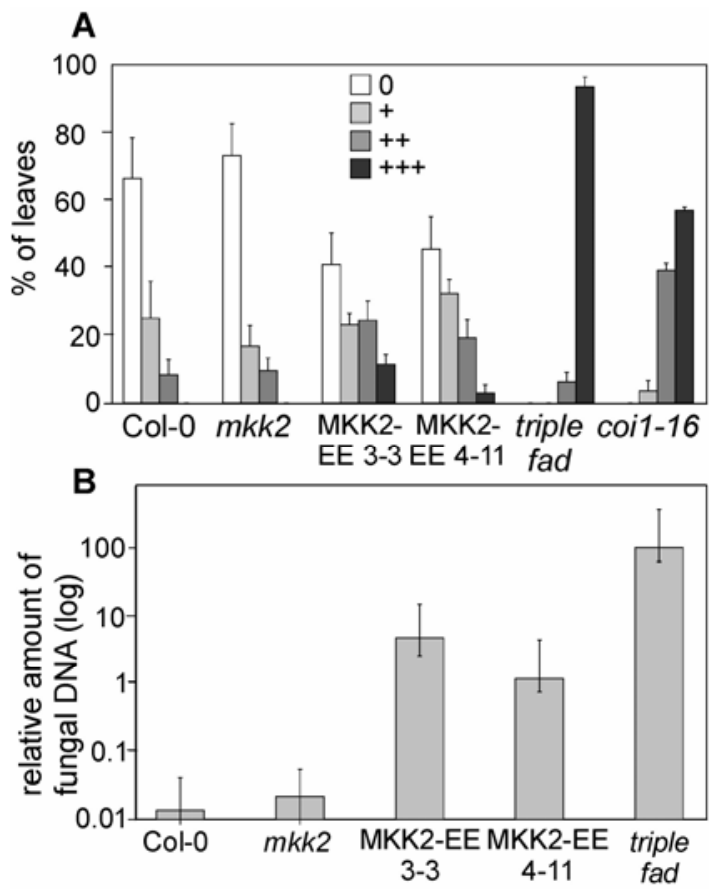

Fig. 4. Mitogen-activated protein kinase kinase 2 (MKK2-EE) plants are impaired in resistance against infection by Alternaria brassicicola. Both $m k k 2$ null and MKK2-EE plants were compared with wild-type Col-0, coil16, and triple fad mutants upon infection with A. brassicicola. A, Necrotic lesions 7 days postinoculation (dpi). B, Evaluation of symptoms \pm standard error of three (coil-16 and triple fad) to five experiments $7 \mathrm{dpi}$, where $0=$ no symptoms or less than $5 \%$ of the leaf area with symptoms, $+=5$ to $25 \%,++$ $=25$ to $50 \%$, and $+++=$ more than $50 \%$ of the leaf area with necrotic lesions. C, Quantification of fungal growth $7 \mathrm{dpi}$ by quantitative polymerase chain reaction. Bars represent the average amount of fungal DNA in relation to plant DNA and are the means of ten replicates \pm standard error.

gate whether MKK2 may affect tolerance to a necrotroph, $m k k 2$ null and MKK2-EE plants were compared with wildtype, coil-16, and triple fad mutants upon infection with $A$. brassicicola. The state of infection was determined by evaluating the necrotic lesion area and fungal growth from the infected leaves (Fig. 4). In these assays, $m k k 2$ null plants were as resistant to A. brassicicola infection as wild-type Col-0, showing 


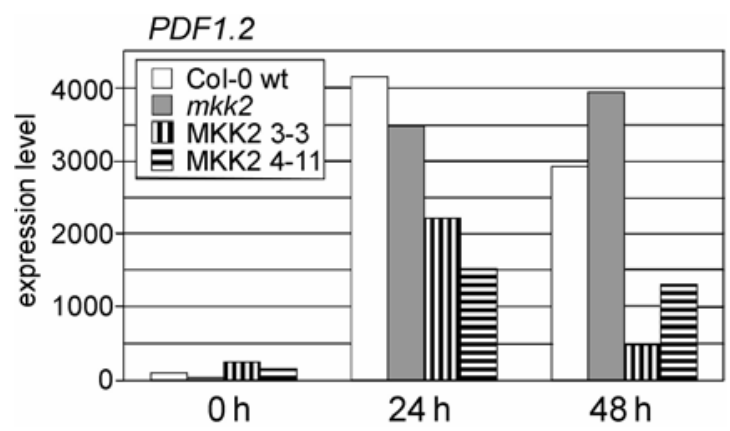

Fig. 5. Alternaria brassicicola-induced gene expression in mitogen-activated protein kinase kinase $2(m k k 2)$ null and MKK2-EE plants. Local leaf samples were collected from 4-week-old Col-0 wild-type, $m k k 2$ null, and MKK2-EE plants at 0,24 , and $48 \mathrm{~h}$ after inoculation with $4 \times 5 \mu \mathrm{l}$ of $A$. brassicicola spore suspension $\left(10^{6}\right.$ spores $\mathrm{ml}^{-1}$ in water). Total RNA was extracted and analyzed by quantitative RT-PCR for PDF1.2 expression. The data were normalized to Tubulin $\alpha$ expression and set to 100 for Col- 0 at $0 \mathrm{~h}$. Values correspond to the average of two biological replicates.

only limited disease symptoms. Although MKK2-EE lines were considerably more sensitive to infection by the fungal pathogen, these plants still were less sensitive than coil-16, triple fad (Fig. 4), or pad3 mutants (data not shown).

Despite the increased sensitivity of MKK2-EE lines against A. brassicicola, the JA marker gene PDF 1.2 is already elevated in noninduced MKK2-EE plants (Table1). Therefore, we determined PDF1.2 levels by reverse-transcription polymerase chain reaction (RT-PCR) 24 and $48 \mathrm{~h}$ after infection with $A$. brassicicola. PDF1.2 transcript amounts strongly increased in wild-type and $m k k 2$ mutants after infection, but the induction was clearly diminished in MKK2-EE lines (Fig. 5). These results show that the MKK2-EE plants are compromised in their resistance against the necrotrophic pathogen $A$. brassicicola and that the enhanced susceptibility is correlating with lower PDF1.2 levels upon A. brassicicola infection.

\section{Enhanced tolerance of $M K K 2-E E$ lines to $E$. carotovora.}

Because the resistance of Arabidopsis plants against infection by the necrotrophic fungus $A$. brassicicola strongly relies on JA signaling, we employed E. carotovora subsp. carotovora strain SCC1 as another pathogen model where disease resistance relies on both SA- and JA-dependent defense responses (Kariola et al. 2003; Li et al. 2004). To determine the contribution of MKK2 to resistance of Arabidopsis toward E. carotovora subsp. carotovora SCC1, mkk2 null and MKK2EE lines as well as wild-type plants were inoculated with $E$. carotovora subsp. carotovora SCC1 and disease symptom development was monitored. Whereas $m k k 2$ null plants displayed disease symptoms and bacterial growth comparable with those of wild-type plants (Fig. 6), MKK2-EE lines showed increased resistance to E. carotovora subsp. carotovora SCC1 infection, such as decreased tissue maceration and spreading of the disease $48 \mathrm{~h}$ after inoculation (Fig 6). These results indicate that $M K K 2$ function also contributes to resistance against $E$. carotovora.

\section{DISCUSSION}

MAPK pathways mediate cellular responses to a great variety of different extracellular signals in plants. We had shown previously that MKK2 functions in abiotic stress signaling and is an upstream regulator of MPK4 and MPK6. In this work, we have analyzed the function of MKK2 in innate immunity against three different pathogens: the bacterial pathogens $P$. syringae pv. tomato DC3000 and E. carotovora subsp. carotovora, as well as the fungal pathogen $A$. brassicicola. We found

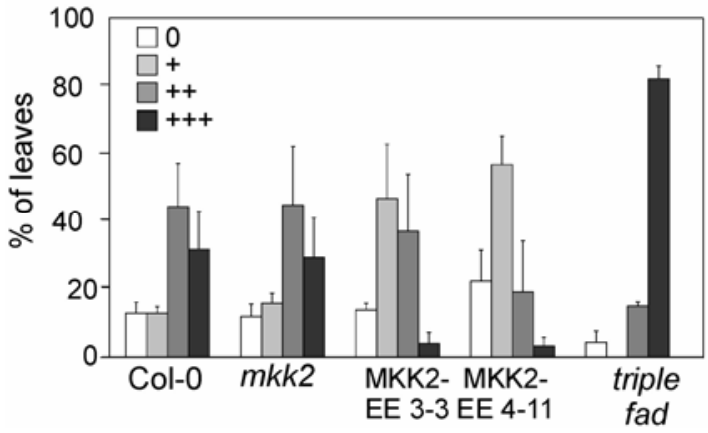

Fig. 6. Enhanced tolerance of mitogen-activated protein kinase kinase 2 (MKK2-EE) lines to Erwinia carotovora. Both $m k k 2$ null and MKK2-EE lines, as well as wild-type Col-0 plants, were inoculated with E. carotovora subsp. carotovora SCC1. Disease symptom development $48 \mathrm{~h}$ after infection symptoms \pm standard error of three experiments was monitored and qualified as following: $0=$ no symptoms, infection dried out at inoculation site; $+=$ infection stopped soon after spreading, less than $50 \%$ of the leaf area macerated; $++=$ infection spreads to more than $50 \%$ of the leaf area; and $+++=$ infection spreads systemically, infected leaf completely macerated.

that $M K K 2-E E$ lines are more resistant to $P$. syringae pv. tomato DC3000 and E. carotovora subsp. carotovora SCC1, but more sensitive to A. brassicicola. These data demonstrate that MKK2 is involved in transducing both abiotic and biotic signals in Arabidopsis.

\section{Plants expressing constitutively active MKK2 show enhanced resistance against $P$. syringae pv. tomato $\mathrm{DC} 3000$ and \\ E. carotovora subsp. carotovora SCC1.}

By yeast two-hybrid analysis, MPK4 and MPK6 were identified as the strongest interactors with MKK2, and both MPK4 and MPK6 were activated by MKK2 in vitro and in vivo (Teige et al. 2004). MPK4 and MPK6 are among the most prominent kinases and can be activated by both abiotic and biotic stresses (Nakagami et al. 2005). Interestingly, whereas mpk4 mutants show enhanced resistance (Petersen et al. 2000), mpk6-silenced lines are compromised in their resistance against infection by $P$. syringae pv. tomato DC3000 (Menke et al. 2004). In our present work, we found that plants with constitutive MKK2 activity showed increased resistance against P. syringae pv. tomato DC3000 and E. carotovora subsp. carotovora $\mathrm{SCC} 1$, suggesting that MKK2 also is involved in mediating innate immunity. However, $m k k 2$ null plants were hardly more sensitive to bacterial infection by $P$. syringae pv. tomato DC3000. On the other hand, $m k k 2$ null plants are clearly hypersensitive to abiotic stresses such as freezing and high salt concentrations (Teige et al. 2004), which indicates that another MAPKK can functionally substitute for MKK2 deficiency in pathogen defense but not in abiotic stress responses. A possible candidate for this function could be the closely related MAPKK MKK1, which is activated in response to various abiotic stresses (Matsuoka et al. 2002), but cross-talk with other MAPK pathways also might be a possible scenario, because lines expressing constitutively active MKK2 show sixfold increased expression levels of MKK5, leaving it an open question as to which MAPKK can truly substitute for MKK2 upon pathogen interactions.

\section{Upregulation of genes for synthesis}

of ET and JA is not correlated with increased levels of hormones in plants expressing constitutively active MKK2.

MKK2-EE plants showed upregulation of ACC synthase ACS6, lipoxygenase, and OPR3 (Table 1), suggesting that these 
plants might accumulate increased levels of ET and JA. For this purpose, we decided to determine the amounts of SA, ET, and JA in $m k k 2$ null, MKK2-EE, and wild-type plants. The amounts of SA, ET, and JA were not strongly different between $m k k 2$ null, MKK2-EE, and wild-type control plants under ambient growth conditions. ET amounts increased in all plant lines at $48 \mathrm{~h}$ after infection by $P$. syringae pv. tomato DC3000. $\mathrm{JA}$ an SA levels also increased in wild-type and $m k k 2$ null mutants upon bacterial infection, but MKK2-EE lines showed lower SA and clearly less JA accumulation, suggesting that MKK2 functions in modulating JA synthesis in response to pathogen infection. The increased levels of lipoxygenase and OPR3 transcripts in MKK2-EE lines could be a consequence of a defective feedback pathway. Whether JA signaling also affects gene expression of ACS6 is not clear, but might be a consequence of cross-talk between the JA and ET pathways. Moreover, enhanced basal levels of JA-responsive genes do not always correlate with increased JA levels (Li et al. 2004) and might reflect alterations in modulation of JA perception or cross-talk with other signaling pathways.

\section{Plants expressing constitutively active MKK2 are compromised in resistance against infection by the necrotrophic fungus $A$. brassicicola.}

If JA synthesis is impaired in response to pathogen infection in MKK2-EE plants, it was expected that these plants should be compromised in their resistance against necrotrophic pathogens. Whereas $m k k 2$ null plants were as resistant to A. brassicicola infection as wild-type plants, MKK2-EE lines were considerably more sensitive to infection by the fungal pathogen. However, MKK2-EE plants were still more resistant than coil-16, triple fad (Fig. 4), or pad3 mutants (not shown). The increased sensitivity of MKK2-EE plants to A. brassicicola is accompanied by lower induction of PDF1.2 24 and 48 hpi (Fig. 5). PDF1.2 expression in Arabidopsis is enhanced after pathogen and superoxide anion-generating paraquat treatment and requires functional ET and JA signaling (Penninckx et al. 1998). Therefore, our results suggest that the impaired JA synthesis or signaling may underlie the sensitivity of MKK2-EE plants against infection by the necrotrophic pathogen $A$. brassicicola. However, we cannot rule out the possibility that other signaling pathways modulating ET perception or oxidative stress signaling are affected in the MKK2-EE lines as well.

Interestingly, MKK2-EE plants were more resistant to another necrotroph, the bacterial pathogen E. carotovora (Fig. 6). Recent publications point to a differential regulation of defense against $E$. carotovora than to $A$. brassicicola and show that partial suppression of JA defense and increased oxidative stress and SA signaling enhances resistance against E. carotovora strain SCC1 (Kariola et al. 2005; Li et al. 2006).

\section{Does MKK2 function}

\section{in integrating abiotic and biotic stress signaling?}

Overall, MPK4 and MPK6 were identified as in vivo targets of MKK2, showing that MKK2 mediates cold and salt stress signaling via MPK4 and MPK6 (Teige et al. 2004). Whereas MPK6 has been accepted to function as a general mediator of biotic and abiotic stresses, the role of MPK4 is less clear. Petersen and associates (2000) postulated that MPK4 is a negative regulator of systemic acquired disease resistance. Multiple studies have shown that MPK4 and MPK6 are both involved in mediating recognition of pathogen-associated molecular patterns and wounding, as well as various abiotic stresses (Asai et al. 2002; Ichimura et al. 2000; Nakagami et al. 2006; Teige et al. 2004). MPK4 and MPK6 can be activated by MKK2 in response mainly to abiotic stresses and by MKK1 upon bacterial and fungal elicitors (Teige et al. 2004). However, bacterial infection with $P$. syringae pv. tomato DC 3000 instead of elicitors alone also triggers enhanced activation of MPK4 in MKK2-EE lines (Fig. 2). These results suggest that MKK1 and MKK2 might play largely different roles in stress signaling. In agreement with this model, it was found recently that $m k k l$ mutants are compromised in resistance to $P$. syringae pv. tomato DC 3000 (Meszaros et al. 2006). In contrast, we show here that $m k k 2$ plants are hardly affected in resistance to three different pathogen systems, including $P$. syringae $\mathrm{pv}$. tomato DC 3000. These results suggest that MKK1 and MKK2 contribute to a large degree to different signaling modules with specialized roles. Therefore, the identification of the components constituting different MKK modules should be an important future task for furthering our understanding of these important signaling pathways.

\section{MATERIALS AND METHODS}

\section{Plant material.}

The Arabidopsis ecotype Columbia (Col-0) was used as genetic background. The $m k k 2$ T-DNA null line (Garlic_511_H01.b.1a.Lb3Fa) was obtained from the Syngenta Arabidopsis Insertion Library, Torrey Mesa Research Institute (San Diego, CA, U.S.A.) and characterized as reported (Teige et al. 2004). Plants expressing constitutively active MKK2-EE were produced using the binary expression vector pGreenII 0029 (Hellens et al. 2000) under control of the 35S promoter and transformed as an MYC-epitope-tagged MKK2 version using the floral dipping method (Clough and Bent 1998) into Col-0 wild-type plants. Seed of transformed plants were selected and characterized as described (Teige et al. 2004). Seed of the fatty acid desaturase triple fad (fad3-2/fad7-2/fad8) mutant were provided by J. Browse (Washington State University, Pullman, U.S.A.), and seed of JA-insensitive coil-16 by J. Turner (University of East Anglia, Norwich, U.K.). Seed were germinated in $0.5 \times$ Murashige Skoog (MS) medium (Sigma, St. Louis), and plants were grown under $50-\mu \mathrm{E}$ cool white fluorescent light and long day conditions $(16 \mathrm{~h}$ of light and $8 \mathrm{~h}$ of dark). Arabidopsis protoplasts were prepared from a suspension culture as described (Cardinale et al. 2000; Mathur and Koncz 1997). For hormone analysis and pathogen treatment, 3- to 4-week-old plants were cultivated under a 12-h light period at $22^{\circ} \mathrm{C}$ with $50-\mu \mathrm{E}$ cool white fluorescent light on a 1:1 mixture of vermiculite and peat (Finnpeat; B2 Kekkilo Oyj, Tuusula, Finland).

\section{Molecular cloning and construction of expression vectors.}

The open reading frames of MPK4, MPK6, and MKK2 originally were amplified from a cDNA library (Minet et al. 1992) with an NcoI restriction site at the $5^{\prime}$ end and an NotI restriction site in front of the stop codon. The NotI restriction site at the $3^{\prime}$ end was used to introduce a c-MYC epitope as a NotI/Not I cassette. The constitutively active MKK2 allele MKK2-EE was generated by changing the putative phosphorylation sites from threonine to glutamic acid residues (T220E and $\mathrm{T} 226 \mathrm{E})$.

\section{Protein extracts from Arabidopsis leaves.}

Protein extracts were prepared in Lacus buffer $(25 \mathrm{mM}$ Tris, $\mathrm{pH} 7.8,75 \mathrm{mM} \mathrm{NaCl}, 10 \mathrm{mM} \mathrm{MgCl}_{2}, 15 \mathrm{mM}$ EGTA, $1 \mathrm{mM}$ dithiothreitol, $1 \mathrm{mM} \mathrm{NaF}, 0.5 \mathrm{mM} \mathrm{NaVO}, 15 \mathrm{mM} \beta$-glycerophosphate, $15 \mathrm{mM}$ p-nitrophenylphosphate, $0.1 \%$ Tween $20,0.5 \mathrm{mM}$ phenylmethylsulfonyl fluoride, leupeptin at 5 $\mu \mathrm{g} / \mathrm{ml}$, and aprotinin at $5 \mu \mathrm{g} / \mathrm{ml}$ ). Protein extracts were prepared by grinding $200 \mathrm{mg}$ of leaf material in $200 \mu \mathrm{l}$ of Lacus buffer and sea sand (Bögre et al. 1999). 
Immunocomplex kinase assays.

Immunocomplex kinase assays were done according to Cardinale and associates (2002).

\section{Pathogen treatments of plants.}

P. syringae pv. tomato DC3000 was cultivated in King's B medium, and the cells were pelleted, resuspended, and diluted in $10 \mathrm{mM} \mathrm{MgSO}_{4}$ and $0.02 \%$ Silwet-77 to a concentration of 2 $\times 10^{5}$ to $8 \times 10^{6} \mathrm{CFU} \mathrm{ml}{ }^{-1}$. Plants were infected by dipping and bacterial growth was assessed by plating dilution series of leaves ground in $10 \mathrm{mM} \mathrm{MgSO}{ }_{4}$ on King's B plates containing rifampicin at $25 \mu \mathrm{M} \mathrm{ml}^{-1}$ as described (Weigel and Glazebrook 2002). E. carotovora subsp. carotovora SCC1 (Pirhonen and Palva 1988) was cultured overnight at $28^{\circ} \mathrm{C}$ in Luria-Bertani medium. Bacteria were harvested by centrifugation, resuspended in $50 \mathrm{mM} \mathrm{NaCl}$, diluted to $10^{6} \mathrm{CFU} \mathrm{ml} \mathrm{m}^{-1}$, and applied as 5- $\mu$ l droplets on leaves on plants kept at $>95 \%$ relative humidity after infection. Symptoms were monitored $48 \mathrm{hpi}$ and the bacterial growth was determined by homogenizing the infected plants in $10 \mathrm{ml}$ of $0.9 \% \mathrm{NaCl}$ and plating serial dilutions on Luria plates containing ampicillin at $50 \mu \mathrm{g} \mathrm{ml}^{-1}$. A . brassicicola (strain 567.77; Centraalbureau voor Schimmelcultures, Utrecht, The Netherlands) was maintained on potato carrot extract agar and spore suspensions (conidial spores at 5 to $10 \times 10^{5} \mathrm{ml}^{-1}$ in potato dextrose broth) were applied on leaves as $5-\mu l$ drops after making a small wound with a pipette tip. After inoculation, plants were kept at $>95 \%$ relative humidity and symptoms were assessed 7 days postinoculation. For assessing fungal growth, single treated and control leaves were frozen in liquid nitrogen in 10 replicates on the seventh day after infection. Relative fungal biomass was determined by quantitative PCR on an ABI Prism 7000 Sequence Detection System (Applied Biosystems, Foster City, CA, U.S.A.) as described (Kariola et al. 2005).

\section{Plant hormone measurements.}

ET emission was quantified as described (Vahala et al. 2003) by putting whole rosettes of 2-week-old plants grown on MS/2 medium with wet filter paper in a 25-ml airtight glass vial. After $2 \mathrm{~h}$ of incubation in the dark, a 1-ml sample was taken with a disposable syringe and analyzed with a gas chromatograph (Varian 3700, Palo Alto, CA, U.S.A.) equipped with a poropax Q column ( 80 to 100 mesh, $1 \mathrm{~m}$ by $3.2 \mathrm{~mm}$ ) and flame ionization detection. Carrier gas was helium (flow rate: $30 \mathrm{ml} \mathrm{min}^{-1}$ ) and column, injector, and detector temperatures were 40,150 , and $200^{\circ} \mathrm{C}$, respectively.

SA and JA were analyzed by using the vapor-phase extraction method described by Schmelz and associates (2003). Internal standards were $40 \mathrm{ng}$ of ${ }^{13} \mathrm{C}_{1}$-SA and $20 \mathrm{ng}$ of dihydrojasmonic acid (Montesano et al. 2005) in each sample. Gas chromatography-mass spectrometry (GC-MS) analysis was performed on a Trace-DSQ (Thermo) in the single ion monitoring mode on a ZB-35 capillary GC column (35\% phenyl- and $65 \%$ methylpolysiloxane, $30 \mathrm{~m}$ by $0.25 \mathrm{~mm}$ by $0.25 \mu \mathrm{m}$ ) with splitless injection and $230^{\circ} \mathrm{C}$ injector temperature. The column was held at $40^{\circ} \mathrm{C}$ for $1 \mathrm{~min}$ after injection, then heated by $15^{\circ} \mathrm{C}$ $\mathrm{min}^{-1}$ to $250^{\circ} \mathrm{C}$, held for $4 \mathrm{~min}$, and heated by $20^{\circ} \mathrm{C} \mathrm{m^{-1 }}$ to $300^{\circ} \mathrm{C}$ final temperature (kept for $3 \mathrm{~min}$ ) with helium as carrier gas (flow, $1 \mathrm{ml} \mathrm{min}^{-1}$ ).

\section{RNA analyses with real-time PCR.}

Gene expression was quantified by RT-PCR as described previously (Brader et al. 2006) using specific primers 5'TCTTTGCTGCTTTCGACG-3' and 5'-AAACCCCTGACCAT GTCCC-3' for PDF1.2 (AT5G44420) and 5'-TCCATCCTCCT CGACAATGAA-3' and 5'-AAGGCACCATCAAACCTCAG A-3' for Tubulin $\alpha$ TUA4 (AT1G04820).

\section{ACKNOWLEDGMENTS}

This work was supported by grants from the Austrian Science Foundation, the Vienna Science and Technology Fund, the European Community, the Academy of Finland, and from Biocenter Helsinki. We thank J. Turner for kindly providing us coil-16 and J. Browse for triple fad mutant seed.

\section{LITERATURE CITED}

Asai, T., Tena, G., Plotnikova, J., Willman, M. R., Chiu, W. L., GomezGomez, L., Boller, T., Asubel, F. M., and Sheen, J. 2002. MAP kinase signaling cascade in Arabidopsis innate immunity. Nature 415:977-983.

Bögre, L., Calderini, O., Binarova, P., Mattauch, M., Till, S, Kiegerl, S., Jonak, C., Pollaschek, C., Barker, P., Huskisson, N. S., Hirt, H., and Heberle-Bors, E. 1999. A MAP kinase is activated late in plant mitosis and becomes localized to the plate of cell division. Plant Cell 11:101114.

Brader, G., Mikkelsen, M. D., Halkier, B. A., and Palva, E. T. 2006. Altering glucosinolate profiles modulates disease resistance in plants. Plant J. 46:758-767.

Cardinale, F., Jonak, C., Ligterink, W., Niehaus, K., Boller, T., and Hirt, H. 2000. Differential activation of four specific MAPK pathways by distinct elicitors. J. Biol. Chem. 275:36734-36740.

Cardinale, F., Meskiene, I., Ouaked, F., and Hirt, H. 2002. Convergence and divergence of stress-induced mitogen-activated protein kinase signaling pathways at the level of two distinct mitogen-activated protein kinase kinases. Plant Cell 14:703-711.

Chang, L., and Karin, M 2001. Mammalian MAP kinase signalling cascades. Nature 410:37-40.

Clough, S. J., and Bent, A. F. 1998. Floral dip: A simplified method for Agrobacterium -mediated transformation of Arabidopsis thaliana. Plant J. 16:735-743.

Davis, R. J. 2000. Signal transduction by the JNK group of MAP kinases. Cell 103:239-252.

Desikan, R., Hancock, T. J., Ichimura, K., Shinozaki, K., and Neill, S. T. 2001. Harpin induces activation of the Arabidopsis mitogen activated protein kinases AtMPK4 and AtMPK6. Plant Physiol. 126:1579-1587.

Droillard, M.-J., Boudsoq, M., Barbier-Brygoo, H., and Lauriere, C. 2002. Different protein kinase families are activated by osmotic stresses in Arabidopsis thaliana cell suspensions. FEBS (Fed. Eur. Biol. Soc.) Lett. 527:43-50.

Fowler, S., and Thomashow, M. 2002. Arabidopsis transcriptome profiling indicates that multiple regulatory pathways are activated during cold acclimation in addition to the CBF cold response pathway. Plant Cell 14:1675-1690.

Gustin, M. C., Albertyn, J., Alexander, M., and Davenport, K. 1998. MAP kinase pathways in the yeast Saccharomyces cerevisiae. Microbiol. Mol. Biol. Rev. 62:1264-1300.

Hellens, R. P., Edwards, E. A., Leyland, N. R., Bean, S., and Mullineaux, P. M. 2000. pGreen: A versatile and flexible binary Ti vector for Agrobacterium-mediated plant transformation. Plant Mol. Biol. 42:819-832.

Herskowitz, I. 1995. MAP kinase pathways in yeast: For mating and more. Cell 80:187-197.

Hohmann, S. 2002. Osmotic stress signaling and osmoadaptation in yeasts. Microbiol. Mol. Biol. Rev. 66:300-371.

Huang, Y., Li, H., Gupta, R., Morris, P. C., Luan, S., and Kieber, J. J. 2000. ATMPK4, an Arabidopsis homologue of mitogen-activated protein kinase, is activated in vitro by AtMEK1 through threonine phosphorylation. Plant Physiol. 122:1301-1310.

Ichimura, K., Mizoguchi, T., Yoshida, R., Yuasa, T., and Shinozaki, K. 2000. Various abiotic stresses rapidly activate Arabidopsis MAP kinases ATMPK4 and ATMPK6. Plant J. 24:655-665.

Jin, H., Liu, Y., Yang, K. Y., Kim, C. Y., Baker, B., and Zhang, S. 2003. Function of a mitogen-activated protein kinase pathway in $\mathrm{N}$ gene-mediated resistance in tobacco. Plant J. 33:719-731.

Jonak, C., Ökresz, L., Bögre, L., and Hirt, H. 2002. Complexity, cross talk and integration of plant MAP kinase signaling. Curr. Opin. Plant Biol 5:415-424.

Kariola, T., Palomäki, T. A., Brader, G., and Palva, E. T. 2003. Erwinia carotovora subsp. carotovora and Erwinia-derived elicitors HrpN and PehA trigger distinct but interacting defense responses and cell death in Arabidopsis. Mol. Plant-Microbe Interact. 16:179-187.

Kariola, T., Brader, G., Li, J., and Palva, E. T. 2005. Chlorophyllase 1, a damage control enzyme, affects the balance between defense pathways in plants. Plant Cell 17:282-294.

Kovtun, Y., Chiu, W.-L., Tena, G., and Sheen, J. 2000. Function analysis of oxidative stress-activated mitogen-activated protein kinase cascade in plans. Proc. Natl. Acad. Sci. U.S.A. 97:2940-2945.

Kreps, J. A., Wu, Y., Chang, H. S., Zhu, T., Wang, X., and Harper, J. F. 
2002. Transcriptome changes for Arabidopsis in response to salt, osmotic, and cold stress. Plant Physiol. 130:2129-2141.

Li, J., Brader, G., and Palva, E. T. 2004. The WRKY70 transcription factor: A node of convergence for jasmonate-mediated and salicylate-mediated signals in plant defense. Plant Cell 16:319-331.

Li, J., Brader, G., Kariola, T., and Palva, E. T. 2006. WRKY70 modulates the selection of signaling pathways in plant defense. Plant J. 46:477-491.

MAPK group. 2002. Mitogen-activated protein kinase cascades in plants: A new nomenclature. Trends Plant Sci. 7:301-308.

Mathur, J., and Koncz, C. 1997. Establishment and maintenance of cell suspension cultures. Methods Mol. Biol. 82:27-30.

Matsuoka, D., Nanmori, T., Sato, K. I., Fukami, Y., Kikkawa, U., and Yasuda, T. 2002. Activation of AtMEK1, an Arabidopsis mitogen-activated protein kinase kinase, in vitro and in vivo: Analysis of active mutants expressed in E. coli and generation of the active form in stress response in seedlings. Plant J. 29:637-647.

Menke, F. L., van Pelt, J.A., Pieterse, C. M., and Klessig, D. F. 2004. Silencing of the mitogen-activated protein kinase MPK6 compromises disease resistance in Arabidopsis. Plant Cell 16:897-907.

Meszaros, T., Helfer, A., Hatzimasoura, E., Magyar, Z., Serazetdinova, L., Rios, G., Bardoczy, V., Teige, M., Koncz, C., Peck, S., and Bogre, L. 2006. The Arabidopsis MAP kinase kinase MKK1 participates in defence responses to the bacterial elicitor flagellin. Plant J. 48:485-498.

Minet, M., Dufour, M. E., and Lacroute, F. 1992. Complementation of Saccharomyces cerevisiae auxotrophic mutants by Arabidopsis thaliana cDNAs. Plant J. 2:417-422.

Mizoguchi, T., Ichimura, K., Irie, K., Morris, P., Giraudat, G., Matsumoto, K., and Shinozaki, K. 1998. Identification of a possible MAP kinase cascade in Arabidopsis thaliana based on pairwise yeast two-hybrid analysis and functional complementation tests of yeast mutants. FEBS (Fed. Eur. Biol. Soc.) Lett. 437:56-60.

Montesano, M., Brader, G., Ponce De Leon, I., and Palva, E. T. 2005. Multiple defence signals induced by Erwinia carotovora ssp. carotovora elicitors in potato. Mol. Plant Pathol. 6:541-549.

Nakagami, H., Pitzschke, A., and Hirt, H. 2005. Emerging MAP kinase pathways in plant stress signalling. Trends Plant Sci. 10:339-346.

Nakagami, H., Soukupova, H., Schikora, A., Zarsky, V., and Hirt, H. 2006. A mitogen-activated protein kinase kinase kinase mediates reactive oxygen species homeostasis in Arabidopsis. J. Biol. Chem. 281:3869738704.

Nühse, T. S., Peck, S. C., Hirt, H., and Boller, T. 2000. Microbial elicitors induce activation and dual phosphorylation of the Arabidopsis thaliana MAPK6. J. Biol. Chem. 275:7521-7526.

O'Rourke, S. M., Herskowitz, I., and O'Shea, E. K. 2002. Yeast go the whole HOG for the hyperosmotic response. Trends Genet. 18:405-412.

Penninckx, I. A., Thomma, B. P., Buchala, A., Metraux, J.-P., and Broekaert, W. F. 1998. Concomitant activation of jasmonate and ethylene response pathways is required for induction of a plant defensin gene in Arabidopsis. Plant Cell 10:210321-13.

Petersen, M., Brodersen, P., Naested, H., Andreasson, E., Lindhart, U., Johansen, B., Nielsen, H. B., Lacy, M., Austin, M. J., Parker, J. E., Sharma, S. B., Klessig, D. F., Martienssen, R., Mattsson, O., Jensen, A. B., and Mundy, J. 2000. Arabidopsis MAP kinase 4 negatively regulates systemic acquired resistance. Cell 103:1111-1120.

Pirhonen, M., and Palva, E. T. 1988. Occurrence of bacteriophage T4 receptor in Erwinia carotovora. Mol. Gen. Genet. 214:170-172.

Schmelz, E. A., Engelberth, J., Alborn, H. T., O'Donnell, P., Sammons, M., Toshima, H., and Tumlinson, J. H., III. 2003. Simultaneous analysis of phytohormones, phytotoxins, and volatile organic compounds in plants. Proc. Natl. Acad. Sci. U.S.A. 100:10552-10557.

Seki, M., Narusaka, M., Ishida, J., Nanjo, T., Fujita, M., Oono, Y., Kamiya, A., Nakajima, M., Enju, A., Sakurai, T., Satou, M., Akiyama, K., Taji, T., Yamaguchi-Shinozaki, K., Carninci, P., Kawai, J., Hayashizaki, Y., and Shinozaki, K. 2002. Monitoring the expression profiles of 7000 Arabidopsis genes under drought, cold and high-salinity stresses using a full-length cDNA microarray. Plant J. 31:279-292.

Teige, M., Scheikl, E., Eulgem, T., Doczi, F., Ichimura, K., Shinozaki, K., Dangl, J. L., and Hirt, H. 2004. The MKK2 pathway mediates cold and salt stress signaling in Arabidopsis. Mol. Cell 15:141-152.

Tena, G., Asai, T. Chiu, W. L., and Sheen, J. 2001. Plant mitogen-activated protein kinase signaling cascades. Curr. Opin. Plant Biol. 4:392-401.

Thomma, B. P., Eggermont, K., Penninckx, I. A., Mauch-Mani, B. Vogelsang, R., Cammue, B. P., and Broekaert, W. F. 1998. Separate jasmonate-dependent and salicylate-dependent defense-response pathways in Arabidopsis are essential for resistance to distinct microbial pathogens. Proc. Natl. Acad. Sci. U.S.A. 95:15107-15111.

Thomma, B. P., Nelissen, I., Eggermont, K., and Broekaert, W. F. 1999. Deficiency in phytoalexin production causes enhanced susceptibility of Arabidopsis thaliana to the fungus Alternaria brassicicola. Plant J. 19:163-171.

Vahala, J., Keinänen, M., Schützendübel, A., Polle, A., and Kangasjärvi, J. 2003. Differential effects of elevated ozone on two hybrid aspen genotypes predisposed to chronic ozone fumigation. Role of ethylene and salicylic acid. Plant Physiol. 132:196-205.

Weigel, D., and Glazebrook, J. 2002. Arabidopsis: A Laboratory Manual. Cold Spring Harbor Laboratory Press, Cold Spring Harbor, NY, U.S.A.

Zhang, S., and Klessig, D. F. 2001. MAPK cascades in plant defence signaling. Trends Plant Sci. 6:520-526. 